\title{
BOAVENTURA DE SOUSA SANTOS: POR UMA NOVA GRAMÁTICA DO POLÍTICO E DO SOCIAL
}

Marcus Abílio Pereira

Ernani Carvalho

É insustentável a situação de, por exemplo, as ciências sociais continuarem a descrever e interpretar o mundo em função de teorias, de categorias e de metodologias desenvolvidas para lidar com as sociedades modernas do Norte, quando a maioria das sociedades não só apresenta características e dinâmicas históricas diferentes, como tem gerado as suas próprias formas de conhecimento das suas experiências sociais e históricas e produzido contribuições significativas para as ciências sociais, ainda que remetidas para as margens destas (SANTOS ET AL., 2004, p. 21).

Boaventura de Sousa Santos é um dos mais influentes sociólogos de língua portuguesa da atualidade. Seus trabalhos podem ser enquadrados em três macroáreas: Direito e Sociedade, Filosofia ou Epistemologia das Ciências Sociais e Democracia. Atuando basicamente nestas três grandes áreas, ele se tornou referência obrigatória nas mais diferentes disciplinas das Ciências Sociais no Brasil (Direito, Educação, Serviço Social, Ciência Política, Sociologia etc.).

Neste paper vamos mapear o pensamento de Santos tomando como base seus estudos em torno da democracia. Como sua trajetória nos estudos da democracia está fortemente vinculada às teorias participativas da democracia, a percepção de suas reflexões caminha ao lado desta literatura. Neste sentido, a nossa reflexão em torno do seu pensamento democrático está também marcada por essa literatura.

O texto está dividido, basicamente, em três sessões. $\mathrm{Na}$ primeira sessão, vamos tratar, de forma breve, o pocisionamento de Santos acerca da teoria social, onde estão dispos- 
tos os enunciados explicativos de sua teoria; na segunda, abordaremos, de forma sintética, o conceito minimalista de democracia e a crítica dos adeptos da democracia participativa; na terceira sessão, apresentaremos o estado da arte das teorias participativas da democracia tomando Santos como vetor da análise.

\section{A teoria social crítica da razão indolente}

Santos (2000) sustenta que estamos vivendo em um momento de transição paradigmática, no qual o paradigma da modernidade se encontra em declínio, em função do colapso do pilar da emancipação no pilar da regulação, fruto da convergência do paradigma da modernidade e do capitalismo. Este período transicional possui duas dimensões principais: uma epistemológica e outra societal. A transição epistemológica ocorre entre o paradigma dominante da ciência moderna e o paradigma emergente (conhecimen46 to prudente para uma vida decente). A transição societal ocorre do paradigma dominante (sociedade patriarcal, produção capitalista, consumismo individualista, identidades fortaleza, democracia autoritária e desenvolvimento global e excludente) para um conjunto de paradigmas que ainda não sabemos exatamente o que vem a ser ${ }^{1}$.

Em sua construção teórica, o autor afirma que o projeto da modernidade possui duas formas de conhecimento: o conhecimento regulação e o conhecimento emancipação. Os pontos extremos do primeiro são o caos (ignorância) e a ordem (conhecimento); do segundo são o colonialismo (ignorância) e a solidariedade (conhecimento). O pilar da regulação é composto pelo Estado, o mercado e a comunidade, enquanto no pilar da emancipação encontramos três formas de racionalidade: a estético-expressiva, a cognitivo-

\footnotetext{
1 O que o autor vai denominar vibrations ascendences, conceito emprestado de Fourier (vide Santos, 2000).
} 
instrumental e por último a racionalidade prático-moral do direito. A absorção do pilar da emancipação pelo pilar da regulação se deu através da convergência entre modernidade e capitalismo e a conseqüente racionalização da vida coletiva baseada apenas na ciência moderna e no direito estatal moderno (Santos, 2000, p. 42). A sobreposição do conhecimento regulação sobre o conhecimento emancipação se deu através da imposição da racionalidade cognitivo-instrumental sobre as outras formas de racionalidade e a imposição do princípio da regulação mercado sobre os outros dois princípios, Estado e comunidade. Portanto, a emancipação esgotou-se na própria regulação e, assim, a ciência tornou-se a forma de racionalidade hegemônica e o mercado, o único princípio regulador moderno. É o que o autor vai definir como a hipercientificização da emancipação e a hipermercadorização da regulação.

Segundo Santos, "o princípio da comunidade e a racionalidade estético-expressiva são as representações mais inacabadas da modernidade ocidental” (2000), e por isso seriam os princípios que poderiam colaborar para a construção de um novo pilar emancipatório.

O princípio da comunidade é "o mais bem colocado para instaurar uma dialética positiva com o pilar da emancipação" (Santos, 2000, p. 75). Duas são as dimensões fundamentais deste princípio: participação e solidariedade. Em função da colonização através do princípio científico, a participação ficou restrita a uma noção de esfera política entendida a partir da concepção hegemônica da democracia: a democracia representativa liberal. $\mathrm{O}$ welfare state foi $\mathrm{o}$ resultado da colonização do princípio da solidariedade.

A racionalidade estético-expressiva foi a que mais ficou fora do alcance da colonização. Assim como a colonização do prazer se deu através do controle das formas de lazer e dos tempos livres, o autor sustenta que: 
"fora do alcance da colonização, manteve-se a irredutível individualidade intersubjetiva do homo ludens, capaz daquilo a que Barthes chamou jouissance, o prazer que resiste ao enclausuramento e difunde o jogo entre os seres humanos. Foi no campo da racionalidade estéticoexpressiva que o prazer, apesar de semi-enclausurado, se pode imaginar utopicamente mais do que semiliberto"(Santos, 2000, p. 76).

A hipercientificização da emancipação diagnosticada por Santos pode ser entendida como uma limitação ao conhecimento emancipação, pois a imposição da ciência sobre o seu duplo na modernidade, o senso comum, acabou por levar às monoculturas das práticas e do saber. A primeira ruptura epistemológica ocorreu quando a ciência se diferenciou do senso comum conservador, hierárquico e autoritário. Esta necessária ruptura permitiu a liberação de energias emanci48 patórias. Mas com o passar do tempo a ciência acabou por se tornar numa forma de conhecimento superior, isolada e intocável. Segundo Santos:

"como qualquer conhecimento especializado e institucionalizado, a ciência tem o poder de definir situações que ultrapassam o conhecimento que delas detém. É por isso que a ciência pode impor, como ausência de preconceito, o preconceito de pretender não ter preconceitos" (2000, p. 107).

Este foi o processo de hipercientificização. Para sairmos dele e recuperarmos o conhecimento emancipação torna-se necessária uma segunda ruptura epistemológica - transformarmos o conhecimento científico (totalizante e antidemocrático) em um novo senso comum. Este novo senso comum é definido como "conhecimento prudente para uma vida decente” (2000, p. 107). As suas características principais 
são a sua praticidade e pragmaticidade, a sua transparência, a sua superficialidade, o seu carácter indisciplinar e nãometódico e, por último, este novo senso comum deve ser retórico e metafórico (2000, p. 108).

$\mathrm{O}$ conhecimento prudente para uma vida decente possui cinco dimensões: a solidariedade, a participação, o prazer, a autoria e a artefactualidade discursiva. As dimensões da solidariedade e da participação estão relacionadas ao princípio da comunidade e as outras três dimensões relacionam-se à racionalidade estético-expressiva. A dimensão da participação é a que nos interessa sobremaneira, pois ela trata do reconhecimento da limitação imposta por uma definição restrita do espaço da política. A proposta do novo senso comum na dimensão política é a repolitização global da vida coletiva (2000, p. 113). Trata-se de uma tentativa de ampliar os espaços da ação política para além do Estado e da esfera pública, vista como reducionista pelo autor. Tal esforço se justifica como estratégia de ampliar o escopo da ação participativa e romper com os monopólios de interpretação impostos pelo paradigma moderno. A partir desta construção teórica podemos perceber a posição que o autor terá em relação ao aumento da participação política dos cidadãos.

\section{Democracia liberal e a crítica participacionista}

A democracia liberal é atualmente a forma de governo mais difundida no planeta e caracteriza-se pelo seu formato representativo com base no sufrágio universal em que a autonomia dos membros eleitos está, necessariamente, vinculada a um conjunto de regras denominadas de Estado de Direito. Dentre os direitos tidos como sagrados na maioria dos países democráticos liberais estão: liberdade de ir e vir; liberdade de expressão, associação e culto; devido processo legal; a propriedade e a igualdade perante a lei. Apesar da forte difusão do modelo liberal democrático, uma parte sig- 
nificativa da população mundial não vive sob os auspícios desta forma de governo.

O colapso do socialismo real (representado principalmente pela fragmentação do bloco soviético) e o surgimento de um "socialismo de mercado" (representado pelo modelo chinês) trouxeram para o debate teórico da democracia um redimensionamento dos seus estudos. O debate deixa de girar em torno da antítese liberdade versus igualdade e passa a concentrar-se na qualidade desta liberdade, ou melhor, na qualidade da democracia.

Boa parte desta reconfiguração foi direcionada para a crítica do modelo de democracia procedimentalista.

"Afirmo preliminarmente que o único modo de se chegar a um acordo quando se fala de democracia, entendida como contraposta a todas as formas de governo autocrático, é o de considerá-la caracterizada por um conjunto de regras (primárias ou fundamentais) que estabelecem quem está autorizado a tomar as decisões coletivas e com quais procedimentos" (Bobbio, 1986, p. 18).

Este conceito minimalista de democracia serve de paradigma para parte significativa de politicólogos e também se tornou ponto de partida para os estudiosos que consideram sua eficácia explicativa da realidade das democracias bastante reduzida. Os defensores da democracia participativa, grupo do qual Boaventura Santos é parte, sustentam que o real sentido da democracia foi esvaziado com o passar dos tempos, e foi reduzido ao simples modelo de seleção de representantes via voto, portanto, sem participação efetiva da sociedade civil organizada. Os defensores da democracia participativa advogam a necessidade de mecanismos de controle da sociedade civil sob os atos do governo, principalmente no que diz respeito à democracia para a esfera social, em que um bom exemplo seria o orçamento participativo. 


\section{Modelos de democracia: as experiências do Sul}

As teorias que iremos analisar nesta seção possuem, à partida, um traço em comum, pois estes autores começam por reconhecer a importância das teorias da transição e consolidação democrática para o debate sobre democracia na América Latina (O’Donnell, Schmitter e Whitehead, 1986; Mainwaring, O’Donnell e Valenzuela, 1992), mas também procuram demonstrar as suas limitações, ao afirmarem que os teóricos da transição, na busca pela consolidação democrática, acabaram por restringir a idéia de democracia aos pressupostos do modelo liberal representativo. A análise da transição democrática e sua posterior consolidação não poderia ficar restrita ao espaço institucional da política, pois esta postura acabaria por ignorar todo um conjunto de práticas cotidianas que demonstravam a necessidade de uma análise mais ampla de relacionamento entre o Estado, as instituições políticas e a sociedade, mostrando que nessas intersecções habita, precisamente, o movimento de construção da democracia (Avritzer e Costa, 2004, p. 704). De acordo com Dagnino, Olvera e Panfichi:

"ao conceber a democracia como mero exercício de representação política (eleitoralmente autorizada) no campo do Estado, se reproduz uma separação conceitual entre sociedade civil e a sociedade política que impede a análise das continuidades entre elas e, portanto, o entendimento da democratização como um processo que se origina na sociedade mesma e transforma" (2006, p. 18)

O debate que vai para além das teorias da transição da democracia se baseia em três pontos: a consolidação da democracia eleitoral na América Latina; uma insatisfação com os resultados dessas democracias em termos de justiça social, eficácia governamental e inclusão política; e, por último, a análise de experimentos de inovação democráti- 
ca que vêm se desenvolvendo em diferentes países do Sul (Dagnino, 2002; Dagnino, Olvera e Panfichi, 2006, p. 13).

Uma das principais contribuições para a análise de outras experiências de participação democrática em países sem esta tradição institucional, fruto de regimes autoritários ou de independências tardias, é o projeto Democratizar a democracia - os caminhos da democracia participativa, organizada por Santos (2003). Trata-se de análise de estudos de caso em diferentes países do Sul ${ }^{2}$. Todos estes estudos de caso têm em comum inovações de participação política para além da noção hegemônica dentro de um sistema democrático institucionalizado. Apesar de colaborar para o mapeamento de diferentes experiências, este projeto não possui, ainda, um quadro teórico ${ }^{3}$. Dada esta limitação, os principais elementos que encontramos nessas experiências que podem colaborar para a elaboração de um quadro teórico foram: o reconhecimento da importância da participação direta dos 52 cidadãos, a partir de uma articulação entre Estado e sociedade civil, para a criação de espaços decisórios em combinação com mecanismos de democracia liberal representativa; a percepção de que a prática democrática fortalece e valoriza a própria democracia, tendo um caráter pedagógico; a importância de analisarmos também as formas de ação direta, tais como paralisações cívicas, passeatas, ocupações, caminhadas; e, por fim, a existência de um conjunto de reivindicações mais amplo, geralmente vinculado a temas culturais, identitários e de reconhecimento social e político.

As experiências democráticas analisadas pelos pesquisadores demonstram que práticas e saberes produzidos em todo o mundo são muito maiores do que o modelo hegemônico procura sustentar, pois elas estão para além daquelas sustentadas pela democracia representativa, sendo a

\footnotetext{
2 Entre eles, Brasil, Colômbia, África do Sul, Portugal, Índia e Moçambique.

${ }^{3}$ Como afirma o próprio organizador dessa coletânea na introdução (Santos, 2003).
} 
democracia um conceito em aberto, em constante desenvolvimento, no qual as diversas práticas participativas possuem um papel determinante. Essa limitação das possíveis interpretações de outras práticas democráticas em função do modelo hegemônico, que procura desqualificá-las ou não reconhecê-las, acaba por inviabilizar uma interpretação coerente dos diferentes processos pelos quais estes países passaram.

Segundo Santos e Avritzer (2003), são dois os elementos que devem ser discutidos para pensarmos um modelo democrático participativo: o procedimentalismo e o papel dos movimentos societários na institucionalização da diversidade cultural. A componente procedimental também está presente nestas experiências, assim como no modelo representativo liberal. No entanto é importante ressaltar que há uma diferença determinante - não se trata apenas de solucionar, como fez Bobbio (1986), a questão da autorização de governos através do procedimentalismo - limitando assim a própria definição da democracia - mas sim de reconhecer que entre procedimentalismo e participação existe uma relação de complementaridade.

O segundo elemento fundamental para pensarmos este modelo participativo relaciona-se ao papel que os movimentos societários devem cumprir no processo de institucionalização da diversidade cultural. A nova ação política dos movimentos sociais teria como objetivo a ampliação do político através da redefinição das práticas societárias. Este processo só se tornaria possível com o reconhecimento da ampliação do espaço da política. A partir da colocação destas novas demandas, a institucionalização da diversidade cultural ocorreria em função de uma nova redefinição da cidadania, de forma tal que esta pudesse abarcar aqueles que por motivos distintos estivessem excluídos do sistema político.

Para este modelo, a democracia é entendida como "uma gramática de organização da sociedade e da relação entre o 
Estado e a sociedade" (Santos e Avritzer, 2003). A importância desta definição dá-se exatamente em função do fato de que as novas experiências participativas ocorreram em países que passaram por uma redemocratização, permitindo assim a própria redefinição do seu significado. Assim:

"todos os casos de democracia estudados iniciam-se com uma tentativa de disputa pelo significado de determinadas práticas políticas, por uma ampliação da gramática social e da incorporação de novos actores ou de novos temas na política" (Santos e Avritzer, 2003).

O momento de refundação da democracia nos estados analisados na pesquisa de Santos têm tem em comum a possibilidade de redefinição, através da via democrática, de uma identidade que havia lhes sido imposta pelos regimes autoritários ou coloniais a que estavam sujeitos. Somente um 54 conceito de democracia que coloque a possibilidade de redefinição contínua do político permitirá o surgimento destas identidades subjugadas pelos colonialismos e autoritarismos.

A participação política possui um papel fundamental neste processo de redescoberta das práticas societárias desses países. É através dela que aqueles deixados à margem poderão ser incluídos dentro do processo democrático, colaborando na própria definição da comunidade em que estão inseridos. A democracia então é "um projeto de inclusão social e de inovação cultural que se coloca como tentativa de instituição de uma nova soberania democrática" (Santos e Avritzer, 2003).

Uma outra formulação teórica que se desenvolve no Sul e que consideramos relevante é a de Dagnino (2002) e Dagnino, Olvera e Panfichi (2006). Nesta proposta teórica, os autores procuram problematizar a discussão sobre a construção democrática a partir de três instrumentos analíticos: primeiro, o reconhecimento da heterogeneidade da 
sociedade civil e do Estado; segundo, o conceito de projetos políticos; e, por último, as trajetórias sociedade civil e sociedade política.

O conceito de projetos políticos é relevante para esta proposta teórica e designa "os conjuntos de crenças, interesses, concepções de mundo, representações do que deve ser a vida em sociedade, que orientam a ação política dos diferentes sujeitos" (Dagnino, Olvera e Panfichi, 2006, p. 38). É através deste conceito que os autores podem reforçar um elemento relevante para a discussão da ampliação democrática, que é o conflito como componente inerente das relações políticas e sociais. Esta ênfase é fundamental para perceber as relações existentes primeiramente dentro da própria sociedade civil (entre seus diferentes atores), entre a sociedade civil e Estado, e dentro do próprio Estado (que também é perpassado por diferentes interesses e percepções de mundo).

O projeto político neoliberal se consolidou no final do século passado em países latino-americanos ${ }^{4}$. Este consenso liberal se desdobra em quatro consensos principais: o consenso econômico neoliberal, o consenso do Estado fraco, o consenso democrático liberal e o consenso do primado do direito e dos tribunais (Santos, 2002). O consenso econômico neoliberal baseia-se em três pontos fundamentais: a liberalização dos mercados, a diminuição da intervenção estatal na economia e a sua submissão aos organismos internacionais de regulação econômica, tais como o FMI e o Banco Mundial. O consenso do Estado fraco sustentava uma idéia de reforma do Estado que tinha como principal motivo sua adequação aos ditames da economia de mercado, de forma a facilitar e garantir o bom funcionamento do capitalismo mundial, e não a busca pela democratização e seu aprofundamento através de novos mecanismos de participação popular. O consen-

${ }^{4}$ Cabe ressaltar que também alguns países africanos, como Moçambique e África do Sul, e países do Leste Europeu que faziam parte da assim chamada "cortina de ferro" se apropriaram deste pacote social e civilizacional (Osório, 2003; Sader, 2003). 
so democrático liberal baseia-se numa concepção minimalista da democracia. Esta concepção, que restringe a participação ao seu mínimo, busca transformar os conflitos inerentes a qualquer sociedade plural em questões meramente tecnocráticas e gerenciais (Dagnino, Olvera e Panfichi, 2006). O último elemento deste consenso é o primado do direito e dos tribunais. Trata-se da criação das condições necessárias para que a economia de mercado possa se desenvolver sem maiores percalços, através da garantia precípua da propriedade privada e da previsibilidade e garantia dos contratos e normas legais que regem as transações econômicas.

O projeto político-participativo procura ampliar a noção da política, ao reconhecer uma heterogeneidade de atores, práticas e temas. O reconhecimento de novas práticas políticas e a emergência de novas temáticas (já afirmado por Santos e Avritzer, 2003) são um contraponto à proposta neoliberal de limitação da noção da política, através 56 da redução dos terrenos, sujeitos, temas e processos considerados como constituidores da política (Dagnino, Olvera e Panfichi, 2006, p. 58). Através da organização da sociedade civil novas práticas democráticas se desenvolveram, preponderantemente as formas de participação direta nos processos de articulação, deliberação e definição de estratégias de ação.

Este processo de organização da sociedade civil levou a um fortalecimento e valorização da própria democracia, reforçando desta forma o seu caráter pedagógico ${ }^{5}$. A participação no espaço público permite a aprendizagem da cidadania, construída paulatinamente através da partilha de experiências distintas no cotidiano.

Por último, a grande contribuição para a discussão de um projeto democrático participativo é a ênfase na disputa

\footnotetext{
${ }^{5}$ Elemento este já presente nas discussões dos teóricos da democracia participativa do Norte na década de 1970, tais como Pateman (1970) e Barber (1984).
} 
pela construção de um projeto político que venha a se tornar hegemônico. O consenso liberal hegemônico (Santos, 2002) nos levou ao dogma da falta de alternativas (Mouffe e Laclau, 1985), o que torna fundamental afirmarmos que há uma disputa política, que existem outros projetos políticos mais participativos e, portanto, mais democráticos do que aqueles com uma visão minimalista da democracia.

\section{Marcus Abílio Pereira}

é professor assistente dos Departamentos de Direito e Ciências Sociais da PUC-MG

\section{Ernani Carvalho}

é professor do Programa de Pós-Graduação em Ciência Política da UFPE e pesquisador da FACEPE/CNPq

\section{Referências bibliográficas}

AVRITZER, L. 2002. Democracy and the public space in Latin America. Princeton: Princeton University Press. ; COSTA, S. 2004. "Teoria crítica, democracia e esfera pública: concepções e usos na América Latina”. DADOS - Revista de Ciências Sociais, Rio de Janeiro, vol. 47, n 4, 2004, pp. 703-728.

; NAVARRO, Z. 2003. A inovação democrática no Brasil: o orçamento participativo. São Paulo: Cortez.

BARBER, B. R. 1984. Strong democracy - Participatory politics for a new age. Berkeley: University of California Press.

BOBBIO, N. 1986. O futuro da democracia - Uma defesa das regras do jogo. Rio de Janeiro: Paz e Terra.

DAGNINO, E. 2002. "Sociedade civil, espaços públicos e construção democrática no Brasil: limites e possibilidades". In: (org.).

Sociedade civil e espaços públicos no Brasil. São Paulo: Paz e Terra. ; OLVERA, A.; PANFICHI, A. (orgs.). 2006. A disputa pela construção democrática na América Latina. São Paulo/Campinas, SP: Paz e Terra/Unicamp.

DAHL, R. A. 1989. Um prefácio à teoria democrática. Rio de Janeiro: Zahar. MAINWARING, S.; O'DONNELL, G.; VALENZUELA, A. (eds.). 1992. Issues in democratic consolidation: the new South American democracies in comparative perspective. Notre Dame: University of Notre Dame Press.

MOUFFE, C.; LACLAU, E. 1985. Hegemonía y estrategia socialista: hacia una 
radicalización de la democracia. $2^{\mathrm{a}}$ ed. Argentina: Fondo de Cultura Económica.

O’DONNEL, G.; SCHMITTER, P. C.; WHITEHEAD, L. 1986. Transições do regime autoritário: América Latina. São Paulo: Vértice.

OSÓRIO, C. 2003. "Poder político e protagonismo feminino em Moçambique". In: SANTOS, B. S. (org.). Democratizar a democracia - Os caminhos da democracia participativa. Porto: Afrontamento.

PATEMAN, C. 1970. Participation and democratic theory. Cambridge: Cambridge University Press.

SADER, E. 2003. "Para outras democracias". In: SANTOS, B. S. (org.). Democratizar a democracia - Os caminhos da democracia participativa. Porto: Afrontamento.

SANTOS, B. S. 2000. A crítica da razão indolente - Contra o desperdício da experiência. São Paulo: Cortez.

2002. Reinventar a democracia. $2^{\mathrm{a}}$ ed. Lisboa: Gradiva.

(org.). 2003. Democratizar a democracia - Os caminhos da democracia participativa. Porto: Afrontamento.

. 2005. O Fórum Social Mundial: manual de uso. Porto: Afrontamento. ; AVRITZER, L. 2003. "Para ampliar o cânone democrático". In: (org.). Democratizar a democracia. Porto: Afrontamento. ; MENESES, M. P.; NUNES. J. A. 2004. "Introdução: para ampliar o cânone da ciência: a diversidade epistemológica do mundo". In: . (org.). Semear outras soluções: os caminhos da biodiversidade e dos conhecimentos rivais. Porto: Afrontamento. 
through a brief biography. The second part promotes a critical and comparative analysis of Quemonne's works on Democracy, i.e.: Le Gouvernement de la France sous la Vème République, Les régimes politiques occidentaux and Les politiques institutionnelles. The third part inquires, also critically and comparatively, about Quermonne's thinking on Regionalism: Le système politique de l'Union Européenne, L'Europe et le fédéralisme and L'Europe en quête de légitimité. Finally, this article brings some conclusive considerations, pointing out both the importance of the French, in general, and Quermonne's, in particular, political thought.

Keywords: Democracy; Regionalism; Quermonne: Legitimacy.

\section{BOAVENTURA DE SOUSA SANTOS: POR UMA NOVA GRAMÁTICA DO POLÍTICO E DO SOCIAL}

190 MARCUS ABÍLIO PEREIRA E ERNANI CARVALHO

Neste trabalho, foi mapeado o pensamento de Boaventura Santos tomando como base seus estudos em torno da democracia participativa. Antes, porém, desvendou-se a estrutura de sua teoria social como forma de interpretar melhor sua proposta de ampliação do cânone democrático. Na perspectiva de Santos, a participação política possui um papel fundamental neste processo de redescoberta das práticas societárias. É através dela que aqueles deixados à margem poderão ser incluídos no processo democrático, colaborando na própria definição da comunidade em que estão inseridos. A democracia, então, é um projeto de inclusão social e de inovação cultural que se coloca como tentativa de instituição de uma nova soberania democrática.

Palavras-chave: Teoria democrática; Democracia participativa; Boaventura de Sousa Santos. 


\section{BOAVENTURA DE SOUSA SANTOS: FOR A GRAMMAR OF THE POLITICAL AND THE SOCIAL}

This paper we will map the thought of Boaventura de Sousa Santos about participatory democracy. Before that, however, it will be important to analyse the structure of his social theory as a way to better interpret his proposed expansion of the democratic canon. For the Portuguese thinker, political participation has a key role in the rediscoverying of societal practices. It is through these practices that those individuals left behind could be included in the democratic process and therefore having the chance to work in the very definition of the community to which they are inserted. Democracy, in this view, is then a project of social inclusion and cultural innovation that arises as an attempt to institute a new democratic sovereignty.

Keywords: Democratic theory; Participatory democracy; Boaventura de Sousa Santos.

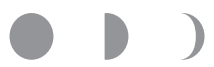

\section{DA FORMAÇÃO À FORMA. AINDA AS “IDÉIAS FORA DO LUGAR”}

\section{BERNARDO RICUPERO}

Uma das formulações mais atacadas, e mal compreendidas, da crítica da cultura brasileira é a das "idéias fora do lugar". Este artigo sugere, porém, que a tese, diferente do que acredita a maior parte de seus críticos, não expressa um fato - a inadequação de certas referências intelectuais a um dado contexto social - mas indica um processo, de formação, que se completaria na forma. A preocupação com tal processo está presente em diferentes âmbitos da vida brasileira; da literatura à economia, passando pela política. Por trás dela se encontra a aspiração de se superar definitivamente a situação de subordinação colonial, estabelecendo-se um quadro de maior autonomia, identificado com a Nação. Mais recentemente, entretanto, tem ganhado força a sensação de que a formação não se completará. 